\title{
Letters
}

\section{Objective assessment of technical skills in surgery}

\section{Assessment should include decision making}

EDITOR-Moorthy et al describe a remarkable new tool to help in the acquisition and assessment of surgical skills. ${ }^{1}$ Assessment is reliable, valid, objective, and reproducible. However, the article concentrates largely on technical skills.

The requirements of a surgeon-which have remained the same over the past 250 years-are sound decision making and surgical prowess. Operations need to be performed well; equally, they need to be done for the right reasons.

The whole process of adult learning is a combination of theoretical knowledge, acquisition of skills, and application of these professionally. ${ }^{2}$ Implicit in this process is a concept of reflective thinking. Reflection integrates new skills and facts with previous knowledge and experience. Without reflection, the learning of new skills happens without being related to a meaningful framework. The last step in this is the critical evaluation of the whole process through internal questioning or self assessment.

The assessment needs to be of both the skills and the decision making process, otherwise the whole exercise becomes simply a way to tick boxes.

Sanjeev Sharma consultant obstetrician and gynaecologist

Southport and Ormskirk NHS Trust, Southport PR8 6PN

sdsharma49@hotmail.com

Competing interests: None declared.

1 Moorthy K, Munz Y, Sarker SK, Darzi A. Objective assessment of technical skills in surgery. BMJ 2003;327:1032-7. (1 November.)

2 Fry H, Ketteridge S, Marshall S, Understanding student learning. In: Fry H, Ketteridge S, Marshall S, eds. A handbook for teaching and learning in higher education. London: Kogan Page, 1999:21-40.

\section{Surgical skills and facts may be best} taught in non-clinical training modules

EDITOR-Moorthy et al highlight the need to assess surgical trainees' skills reliably and accurately, outlining options available to achieve this end. ${ }^{1}$ Inadequate objective skill based assessment and poor knowledge of basic science are major concerns for both trainers and trainees alike.

However, the context in which skills and facts are acquired is just as important as method of assessment. Basic and higher surgical training are currently clinically based, supplemented by courses, educational meetings, and tutorials.
Unfortunately, many trainees attend the course for basic surgical skills well into their training. Some partially fund such courses because of limited deanery budgets or are denied study leave because of service commitments. Training schemes seldom offer revision of anatomy or physiology in the dissection room or laboratory from basic science staff.

In contrast, trainee chartered accountants enjoy the benefit of several structured, month long, free courses between work placements. Pass rates exceed comparable surgical examinations, and trainees receive useful career preparation.

The surgical royal colleges acknowledge that training needs restructuring. ${ }^{2}$ I suggest that protected, structured blocks of teaching and assessing basic sciences and skills should be provided throughout surgical training. Proposed changes to training present an ideal opportunity to implement such modules. ${ }^{3}$

Objections are predictable. It would be costly. Trainees would require release from some service commitments. Postgraduate training would have to be properly organised. Difficulties arise in the objective assessment of trainees. ${ }^{4}$ But if surgical teaching and assessment is to improve then the solution must be more radical than formulating another three day course, or adding an extra examination.

James P B O'Connor anatomy demonstrator Department of Anatomy, University of Manchester, Manchester M13 9PT james.o'connor@man.ac.uk

Competing interests: None declared.

1 Moorthy K, Munz Y, Sarker S K, Darzi A. Objective assessment of technical skills in surgery. BMJ 2003;327:1032-7. (1 November.)

2 Royal College of Surgeons of England. Surgical competence: challenges of assessment in training and practice. London: RCS, 1999.

3 Department of Health. Unfinished business. London: DoH. 2002.

4 Darzi A, Datta V, Mackay S. The challenge of objective assessment of technical skill. Am J Surg 2001;181:484-6.

\section{Treating inguinal hernias}

Editorial does not tell the whole story...

EDITOR-In his editorial Kingsnorth argues that open inguinal hernia repair with the Lichtenstein method is superior to the laparoscopic approach. ${ }^{1}$ We think that this is not the whole story.
In a recent Cochrane review six visceral and seven vascular injuries (in 2498 patients) were reported in the laparoscopic group compared with one and five (in 2758 patients) in the open group. ${ }^{2}$ In the laparoscopic group the convalescence was significantly shorter than after open surgery (7 days, $\mathrm{P}<0.001)$. Furthermore, and probably most importantly, the review found a significant reduction in the rate of chronic groin pain $(290 / 2101 v 459 / 2399$, $\mathrm{P}<0.001)$ after laparoscopic repair, with no difference in recurrence rates after the two procedures.

Although the direct cost of the laparoscopic technique is higher, this difference is eliminated by recommending a convalescence of one week only. ${ }^{3}$

Kingsnorth's concern about the complex nature of the laparoscopic procedure is legitimate, but, as the learning curve is $30-50$ operations, ${ }^{4}$ this problem can be solved by establishing dedicated centres for laparoscopic hernia repair, as is commonly done in many countries when the Lichtenstein procedure is the preferred method.

Laparoscopic hernia repair is not a dangerous procedure. The learning curve can be facilitated by establishing laparoscopic hernia centres, and the cost can be reduced effectively and equalised with the open procedure. Most importantly, laparoscopic hernia repair is followed by much less pain, and this must be one of the top priorities of a responsible surgeon.

Emilie Øberg research fellow emilieberthelsen@hotmail.com

Jacob Rosenberg professor

Department of Surgical Gastroenterology, Gentofte Hospital, University of Copenhagen,

DK-2900 Hellerup, Denmark

Competing interests: None declared.

1 Kingsnorth A. Treating inguinal hernias. $B M J$ 2004:328:59-60. (10 January)

2 McCormack K, Scott NW, Go PM, Ross S, Grant AM; EU Hernia Trialists Collaboration. Laparoscopic techniques versus versurane Database Syst Rev 2003;(1):CD001785.

Swanstrom LL Laparoscopic hernia repairs: the importance of cost as an outcome measurement at the century's end. Surg Clin N Am 2000;80:1341-51.

4 DeTurris SV Cacchione RN, Mungara A, Pecarare A 4 DeTurris SV, Cacchione RN, Mungara A, Pecararo A, erzli GS. Laparoscopic

\section{... and is misleading}

EDITOR-Kingsnorth has misrepresented the role of the laparoscopic hernia repair in his article. ${ }^{1}$ A clinician reading this who has no experience of surgical options for inguinal hernia repair may come away with the impression that laparoscopic repair has largely been dismissed by the surgical 
community and the National Institute for Clinical Excellence (NICE).

Kingsnorth reports that the incidence of chronic groin pain after hernia repair has now overtaken that of hernia recurrence, without making it clear that among the various advantages of laparoscopic hernia repair (less postoperative pain and earlier return to normal activity) chronic groin pain almost never occurs.

The rare but serious complications that he quotes from the European Union's hernia trialists collaboration were for transabdominal pre-peritoneal hernia repairs (as opposed to totally extra peritoneal repairs), ${ }^{2}$ which are not currently recommended by NICE.

The article did not highlight the fact that laparoscopic repair is recommended by NICE for bilateral and recurrent hernia repair. The main objections to laparoscopic repair for primary hernias are apparently financial and not clinical.

Interestingly the illustration of mesh in the preperitoneal space is the mesh placement for laparoscopic not open repairs, although this is not stated in the text. This may further mislead readers who are not aware of these differences into believing this represents mesh replacement for open hernia repair.

Kingsnorth oversees a hernia unit at Plymouth that deals exclusively with open hernia repairs. This might be regarded as a competing interest.

Paul M Peyser consultant gastrointestinal and laparoscopic surgeon

Royal Cornwall Hospital, Truro TR1 3LJ paul.peyser@rcht.cornwall.nhs.uk

Competing interests: PMP performs both open and laparoscopic hernia repairs of the totally extra peritoneal type.

1 Kingsnorth A. Treating inguinal hernias. BMJ 2004;328:59-60. (10 January.)

EU Hernia Trialists Collaboration. Laparoscopic compared with open methods of groin hernia repair: systematic review of randomised controlled trials. Br J Surg
2000;87:860-7. 2000;87:860-7.

National Institute for Clinical Excellence. Guidance on the use of laparoscopic surgery for inguinal hernias. London:
NICE, 2001. (Technology appraisal guidance No 18.)

\section{Author's reply}

EDITOR-Øberg and Rosenberg are keen protagonists of the laparoscopic operation for treating inguinal hernias and propose the establishment of dedicated laparoscopic hernia centres. To train surgeons in one operation in specialised units is clearly impracticable and is not cost effective.

It will take a long time to train a cohort of surgeons proficient in laparoscopic herniorrhaphy on the basis of the data of Bittner et al, who reported over 8000 laparoscopic repairs in eight years, during which they were able to train only eight junior surgeons. ${ }^{1}$ The average general surgeon will repair only 30-40 inguinal hernias yearly. Enthusiastic laparoscopic surgeons, however, are strident in their demands for other surgeons to be converted to this operation with its long learning curve.

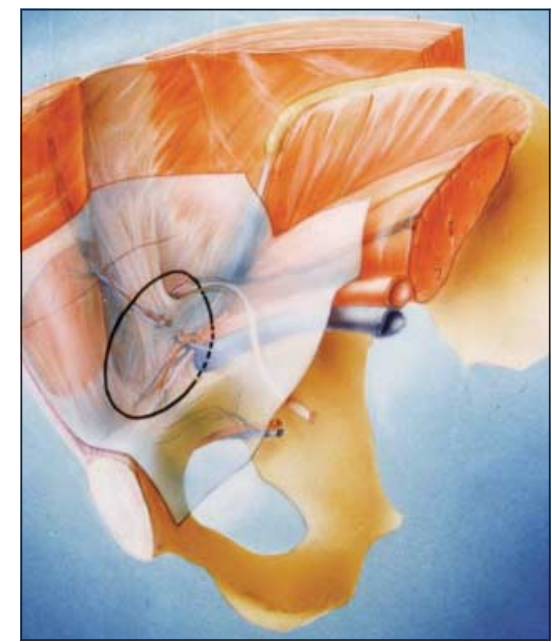

Placement of mesh into the periperitoneal space with wide overlap to prevent recurrence

DeTurris et al, in analysing 38 randomised trials, concluded that their analysis failed to make a convincing case for the superiority of either open or laparoscopic herniorrhaphy, which includes operative time, postoperative pain, return to work, complications, and recurrences. ${ }^{2}$

Peyser's letter is riddled with misleading and inaccurate information. Laparoscopic herniorrhaphy has been largely dismissed by the surgical community: $96 \%$ of UK surgeons, $86 \%$ of US surgeons, and virtually all Japanese surgeons use open repair. ${ }^{3-5}$ There are no hard data for European countries, but in France laparoscopic repair is rapidly declining following guidance from the French equivalent of the National Institute for Clinical Excellence.

Regarding chronic groin pain, the EU Hernia Trials Collaboration has pointed out the large confidence intervals in its analysis and has indicated that a large randomised controlled trial is needed, with specific end points to arrive at definitive conclusions.

The illustration in my editorial and here is for an open mesh placed by the preperitoneal route, as described by Stoppa (figure). The Plymouth Hernia Service not only supports my practice of open inguinal herniorrhaphy but also that of three of my colleagues who undertake laparoscopic repair for bilateral and recurrent inguinal hernias and incisional hernias.

Andrew Kingsnorth professor of surgery

Derriford Hospital, Plymouth PL6 8DH

andrew.kingsnorth@phnt.swest.nhs.uk

1 Bittner R, Schmedt C-G, Schwarz J, Kraft K, Leibl BJ. Laparoscopic transperitoneal procedure for routine repair of groin hernia. BrJ Surg 2002;89:62-6.

2 DeTurris SV, Cacchione RN, Mungara A, Pecorara A, Ferzli GS. Laparoscopic herniorrhaphy: beyond the learning curve. J Am Coll Surg 2002;194: 65-73.

3 Bloor K, Freemantle N, Khadjesan Z, Maynard A. Impact of NICE guidance on laparoscopic surgery for inguinal of NICE guidance on laparoscopic surgery for inguinal
hernias: analysis of interrupted time series. BMJ hernias: analy
2003;326:578.

4 Rutkow IM. Demographic and socioeconomic aspects of Rutkow IM. Demographic and socioeconomic aspects of
hernia repair in the United States in 2003. Surg Clin N hernia repair in the Unie $2003 ; 83: 1450-51$.

5 Omer 2003;83:1450-51. Current practices in adult groin hernias: a survey of Japa-
nese general surgeons. Surg Today 2003;33:155-7.

\section{Prevention of coronary heart disease}

\section{Statins are even less effective than paper} shows

EDITOR-Marshall commendably questions current trends in preventive medicine. ${ }^{1} \mathrm{He}$ looks at cost effectiveness of cardioprotective drug treatment, including simvastatin $40 \mathrm{mg}$, by assessing pooled data from different trials. Treatment effects are balanced with costs. The expenditure for simvastatin $40 \mathrm{mg}$ is calculated as prescribing costs plus additional costs for administration and laboratory tests.

A close look at the heart protection study, $^{23}$ Marshall's main reference for statins, quickly calls this equation into question. Simvastatin $40 \mathrm{mg}$ was less well tolerated and less effective than portrayed by the authors.

Firstly, tolerability: against all claims simvastatin was not well tolerated. A substantial number of patients did not enter the trial after a six week run in before randomisation (63 603 entered the original screening, 32145 went forward to the run in phase and 11609 patients dropped out then).

Secondly, independent treatment effects: Marshall assumes that statins work independently of other cardioprotective treatment as stated in the heart protection study. However, most of the patients in the study did not take appropriate non-statin drug treatment-for example, only $47 \%$ of all patients with peripheral vascular disease were taking aspirin.

Thirdly, reduced treatment effects for women: simvastatin in the heart protection study did not reduce overall mortality in women. ${ }^{4}$ This fact was buried by the researchers using composite end points.

Marshall questions the cost effectiveness of different cardiovascular treatments including statins. The properly interpreted results of the heart protection study lend even more weight to his scepticism.

David Taylor general practitioner principal Birmingham B31 2HZ

Arnold Jenkins general practitioner principal Burnley BB10 1LG

Philipp Conradi part time general practitioner Birmingham B7 5DT pconradi@hotmail.com

Competing interests: None declared.

\footnotetext{
1 Marshall T. Coronary heart disease prevention: insights from modelling incremental cost effectiveness. BMJ 2003;327:1264-7. (29 November.)

2 Heart Protection Study Collaborative Group. MRC/BHF heart protection study of cholesterol lowering with Simvastatin I 20, 536 high risk individuals: a randomised placebo controlled trial. Lancet 2002:360:7-22.

placebo controlled trial. Lancet 2002:360:7-22. MRC/BHF Heart Protection Study Collaborative Group Heart protection study of cholesterol lowering therapy and antioxidant vitamin supplementation in a wide range of patients at increased risk of coronary heart disease
death: early safety and efficacy experience. Eur Heart J
1999:20:7254.

1999;20:7254.
4 Jenkins A. Might money spent on statins be better spent? BMJ 2003;327:933. (18 October.)
} 


\section{Is a cure too expensive?}

EDITOR-As Warburton points out in her editorial, we may soon be able to reduce the event rate in patients at risk of coronary heart disease to towards zero. ${ }^{1}$ The current cocktail of drugs is likely to decrease events by up to $88 \%{ }^{2}$

We have been fortunate that most of the drugs in this cocktail are cheap (aspirin, thiazides, $\beta$ blockers). Marshall in his article shows that aspirin (NHS price $£ 0.18$ per 28 days) is much more cost effective than clopidogrel (NHS price £35.31 per 28 days) and statins (NHS price $£ 29.68$ per 28 days). ${ }^{3}$ I doubt that anybody would have been surprised by this finding.

If we continue to pursue new treatments that will reduce the risks of ischaemic heart disease further they will inevitably be much less cost effective than aspirin. As the event rate goes down with each successful intervention the number needed to treat for each new drug will increase. If we follow the logic expressed in this article then we should give up trying as nothing will ever be as cost effective as aspirin.

The effective cure of the biggest killer in the Western world would have been a triumph for mankind, medicine, and big pharma. It seems that, like going to the moon, it isn't going to be very cost effective.

G Alastair Cooke consultant cardiologist King's Mill Hospital, Mansfield MG17 4JL

alastaircooke@doctors.org.uk

Competing interests: None declared.

1 Warburton RN. What do we gain from the sixth coronary heart disease drug? BMJ 2003:327:1237-8. (29 November.) Wald NJ Iaw MR A strategy to reduce carlioverember.) Wald NJ, Law MR, A strategy to reduce cardiovascular disease by more than $80 \%$. BMJ 2003;326:1419- 0 .

Marshall T. Coronary heart disease prevention: insight cost effectiveness. BMJ 2003;327:1264-7. (29 November.)

\section{Incremental cost effectiveness raises issues}

EDITOR-Marshall seemed not to include the cost to the health system of treatment after a myocardial infarction occurs. ${ }^{1}$ You could go further and estimate the cost to society of prematurely losing productive members.

Say, for example, one myocardial infarction was prevented with treatment $\mathrm{A}$ and two with treatment B in a group of 100 . If A costs $\$ 1$ a year and $B, \$ 10$, then $A$ would be five times as cost effective as B per event prevented. However, if the cost of treatment after an event occurs is high, B could be more cost effective. If they operate independently A and B together could be the best treatment

Marshall might have discussed what dosages of statins were used. In the United States the cost is fairly constant with dose, but the effectiveness for a given patient could change and so would the cost effectiveness.

Marshall assumed a patient (pretreatment) had a $10 \%$ risk of a coronary event over five years-which seems low for a patient seeing a cardiologist-and then applied a relative risk based on other studies. On the basis of a meta-analysis of other studies, out of 100 people who would have had a coronary event, 69 would have been taking a statin, 72 aspirin, and 50 both.
A $10 \%$ risk of a coronary event biases the results towards the lower cost treatment. If you picked a group with an extremely low chance of a coronary event over five years the cheaper treatment would be quite cost effective. Furthermore, were the aspirin and statin groups similar and were they at $10 \%$ coronary risk?

To treat patients at lower risk slightly more aggressively is appropriate. Some, however, might conclude from this study that this might have been done at the expense of those at higher risk or by choosing either statins or aspirin but not both.

William C. D'Avanzo retired

21B Kenneth Stuart Place, Mohegan Lake, NY 10547

davanzo@prodigy.net

Competing interests: None declared.

1 Marshall T. Coronary heart disease prevention: insight from modelling incremental cost effectiveness. $B M$ 2003.327:1264-7. (29 November)

\section{Data in table 2 could be shown more} explicitly for better understanding

EDITOR-The cost effectiveness study published by Marshall is difficult to understand in its technical details not only by average readers but also people with some skill in pharmacoeconomics.

We think that the part of this study that presents the data of the average cost effectiveness (table 1 of the article) is useless because the practical implications of this study, along with the assessment of the pharmacoeconomic profile of the various drugs, rely exclusively on the findings of the incremental cost effectiveness analysis (the data presented in table 2).

Table 2 is not adequately explained by the author. For this reason, we propose a more detailed layout, in which much more information is presented and the labelling of each row is made more explicit (see bmj.com).

Andrea Messori coordinator

andreamessori@interfree.it

Benedetta Santarlasci researcher Laboratorio SIFO di Farmacoeconomia, Careggi University Hospital, 50134 Florence, Italy

Competing interests: None declared.

Marshall T. Coronary heart disease prevention: insight from modelling incremental cost effectiveness. BMJ 2003;327:1264-7. (29 November.)

\section{See table on bmj.com}

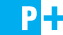

\section{Author's reply}

EDITOR-Correspondents responding to my article on bmj.com raise several interesting issues. ${ }^{1}$ Nevertheless no correspondent disputes either the approach (incremental cost effectiveness analysis) or the fundamental findings: that aspirin and antihypertensive treatment with bendrofluazide and atenolol are markedly more cost effective than statins and clopidogrel.

Conradi et al and O'Donnell indicate that statins may have more side effects than is generally appreciated. Mann doubts the effectiveness of clopidogrel in primary prevention. $^{1}$ Both points strengthen the paper's conclusions. I agree with Mann's suggestion that individuals need information on the risk reduction with treatment in order to decide if it is worth while.

Cooke says that the development of further drugs to prevent coronary heart disease may not be cost effective. It is very efficient to prevent coronary disease by using existing, low cost treatments.

If, as Jacobs says, treatment effects are not independent, second and third treatments may be even less cost effective than the analysis shows. ${ }^{1}$ Under current criteria, $80 \%$ of those eligible for one preventive treatment are eligible for at least two and $53 \%$ are eligible for all three.

Das and Vos suggest oily fish as an intervention. ${ }^{1}$ Wide confidence intervals around the estimated effectiveness of dietary oily fish meant it was excluded from the published paper, however it is probably more cost effective than a statin.

Mihaylova et al suggest further refinements to the model including cost savings from heart disease prevented. They acknowledge that these refinements are unlikely to affect the rankings or overall message. ${ }^{1}$ As the purpose of economic evaluation is to improve decision making it is not clear how further complexity can be justified in terms of better decisions. My analysis includes sufficient information to improve decision making dramatically within preventive cardiology. Complex analysis is not always well understood ${ }^{2}$

Several correspondents refer to an imminent fall in the price of simvastatin. At $£ 4.45$ a pack (containing 28 tablets), simvastatin becomes the third most cost effective intervention. Under these circumstances a rational policy would offer aspirin at 5\% coronary risk, bendrofluazide and atenolol at $7.5 \%$, and simvastatin at $15 \%$. A third

Cost effectiveness of preventive treatments $(£)$ in patients at different degrees of risk if price of simvastatin falls by $85 \%$

\begin{tabular}{lccccccc} 
& \multicolumn{7}{c}{ Five year coronary risk (\%) } \\
\cline { 2 - 9 } & $\mathbf{5}$ & $\mathbf{7 . 5}$ & $\mathbf{1 0}$ & $\mathbf{1 5}$ & $\mathbf{2 0}$ & $\mathbf{2 5}$ & $\mathbf{3 0}$ \\
\hline Treatment & 7900 & 4900 & 3500 & 2200 & 1600 & 1300 & 1100 \\
\hline Aspirin 75mg and follow up & 24000 & 16000 & 12000 & 8000 & 6000 & 4800 & 4000 \\
\hline $\begin{array}{l}\text { Bendrofluazide 2.5mg and } \\
\text { atenolol 50mg }\end{array}$ & 34900 & 23300 & 17500 & 11600 & 8700 & 7000 & 5800 \\
$\begin{array}{l}\text { Simvastatin 40mg } \\
\text { (£4.45 for 28 tablets) }\end{array}$ & 98200 & 65500 & 49100 & 32700 & 24600 & 19600 & 16400 \\
\hline \begin{tabular}{l} 
Enalapril 20mg \\
\hline Clopidogrel 75mg
\end{tabular} & 1054400 & 702900 & 527200 & 351500 & 263600 & 210900 & 175700 \\
\hline
\end{tabular}


antihypertensive drug would never be offered, obviating the need to "treat to target" (table) The onus is now on pharmaceutical manufacturers to provide simvastatin at this cost.

Tom Marshall clinical lecturer

Department of Public Health and Epidemiology, University of Birmingham, Birmingham B15 2TT T.P.Marshall@bham.ac.uk

Competing interests: None declared

1 Electronic responses. Coronary heart disease prevention. bmj.com 2003. bmj.bmjjournals.com/cgi/eletters/327 7426/1264 (accessed 20 Jan 2004). http:// bmj.bmjjournals.com/cgi/content/full/327/7426/1264 (accessed 1 Feb 2004)

2 Burls A, Sandercock J. How to make a compelling submission to NICE: tips for sponsoring organisations. $B M J$ 2003;327:1446-8.

\section{Payment for coroners' postmortem examinations}

\section{Financial gain is pathetic...}

EDITOR-Alcolado remembers as a house officer requesting a postmortem examination and being forced to make it a coroner's at the request of a pathologist. ${ }^{1}$

Firstly, let me make it clear that nobody can force someone to make a death into a coroner's post mortem if a cause of death is established. The doctor simply signs the death certificate to this effect. I know of no pathologist who can bend the ear of the coroner to this extent-rather the opposite. In my experience, cases are often not referred to the coroner that should be, such as postoperative deaths.

Secondly, the idea that the pathologist receives "a substantial payment" for each coroner's post mortem is laughable. I get $£ 78$ for each postmortem case I do, and this often involves four to six hours of work because I deal with complex postoperative deaths that usually require detailed examination and histology. The BMA is looking into the fees for coroners' autopsies and campaigning for a substantial increase. The pathologist who forced Alcolado to turn a case into a coroner's post mortem must have been desperate to waste his or her precious time for $£ 78$.

Finally, all coroners' cases in my hospital are actively used for teaching and audit purposes.

Mary N Sheppard consultant pathologist Royal Brompton and Harefield Hospital Trust, London SW3 6NP

m.sheppard@rbh.nthames.nhs.uk

Competing interests: None declared.

1 Alcolado JC. Death of the teaching autopsy. BMJ 2004;328:165. (17 January.)

\section{... and not part of the equation}

EDITOR-Alcolado in his letter describes a consultant pathologist insisting that a case be referred to the coroner for an autopsy, and he implies that this was for financial gain (which, from his account, seems possible). ${ }^{1}$
Such behaviour by any of the six consultants in my department would be completely unacceptable, and I am sure that most histopathologists in the United Kingdom would agree. His suggestion that financial gain be taken out of the equation could perhaps be applied to many fields of medicine, although the new contract would imply that this is not current policy.

I would gladly stop doing my extracontractual coroners' work and forgo the comparatively small income derived from it. We have recently turned down the offer of an increase in this work, despite what Alcolado views as the "substantial payment" offered.

Simon Rose consultant histopathologist Royal United Hospital, Bath BA1 3NR simon.rose@ruh-bath.swest.nhs.uk

Competing interests: SR performs coronial autopsies.

1 Alcolado JC. Death of the teaching autopsy: hospital and coroners' postmortem examinations are different not least in payment. BMJ 2004;328:165. (17 January.)

\section{Omega 3 fatty acids and cardiovascular disease}

\section{Algae can be source of "fish" oil}

EDITOR-Concern about depletion of fish stocks will not be addressed by supplementing animal feed with fish oil, as suggested by Din et al, ${ }^{1}$ because this requires the harvesting of wild fish to provide the fish oil. Fish farming does not provide a solution as farmed fish contains fewer omega 3 fatty acids, this being dependent on what they are fed-usually wild caught fish products. ${ }^{2}$

The original source of the long chain omega 3 fatty acids found in fish is, however, the chloroplasts of marine algae and phytoplankton at the bottom of the food chain. ${ }^{3}$ In the marine environment polyunsaturated fatty acids may provide the degree of desaturation needed to keep cell membranes fluid in cold water. Rather than genetically modifying terrestrial plants to produce eicosapentaenoic and docosahexanoic acid, marine algae can be cultured industrially to provide the "fish" oil while leaving the fish alone. ${ }^{4}$

If cod liver oil is used as a source of fish oil it is important to remember that this contains a comparatively high concentration of vitamin A, producing a risk of toxicity. ${ }^{5}$

Matthew D Barber specialist registrar in general

surgery
Edinburgh Breast Unit, Western General Hospital,

Edinburgh EH4 2XU

barbermd@hotmail.com

Competing interests: MDB has received research funding from Scotia Pharmaceuticals and Ross Products Division for work involving fish oil based preparations.

1 Din JN, Newby DE, Flapan AD. Omega 3 fatty acids and cardiovascular disease-fishing for a natural treatment. BMJ 2004;328:30-5. (3 January)

Van Vliet T, Katan MB. Lower ratio of n-3 to n-6 fatty acid in cultured than in wild fish. Am J Clin Nutr 1990;51:1-2.

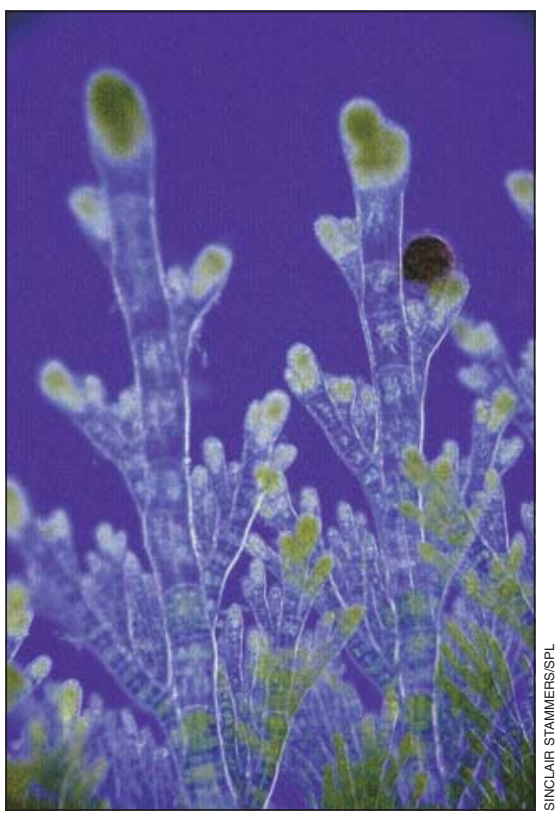

Marine algae: source of omega 3 fatty acids

3 Nordoy A, Dyerberg J. n-3 fatty acids in health and disease J Intern Med 1989;225(suppl 1):S1-3.

4 Wen ZY, Chen F Heterotrophic production of eicosapen4 Wen ZY, Chen F. Heterotrophic production of eicosapentaenoic acid by microalgae. Biotechnol Adv 2003:21:273-94. high-dose fish oil supplements. Chest 1990;97:1260.

\section{Plant sources may be as effective as} oily fish

EDITOR-In their review of omega 3 fatty acids and cardiovascular disease Din et al ignored the plant derived omega 3 fatty acids beyond the initial definitions. ${ }^{1}$

In figure 3 they say that the omega 3 fatty acids from fish oils are metabolites of $\alpha$ linolenic acid (the plant derived source of omega 3 fatty acids). However, they did not say whether $\alpha$ linolenic acid is as effective as oily fish in the beneficial effects described. Is this because no trials exist or trials show less effect?

Din et al comment on concerns about depleting fish stocks and environmental contamination of certain fish. Would suggesting a trial of $\alpha$ linolenic acid supplements or a diet rich in the plant sources of this oil be an option for future research as well as their proposed trial of fish oil supplements?

Olga N Garrard consultant in child and adolescent psychiatry

Canada House, Gillingham ME7 4JL

olga.garrard@icc.wkentmht.nhs.uk

Competing interests: None declared.

1 Din JN, Newby DE, Flapan AD. Omega 3 fatty acids and cardiovascular disease-fishing for a natural treatment. BMJ 2003;328:30-5. (3 January.)

\section{Authors' reply}

EDITOR-Farmed fish such as salmon and trout generally have as much if not more omega 3 fatty acids per gram than wild fish. ${ }^{1}$ However, because farmed fish contain more total fat than wild fish, they have a smaller proportion of omega 3 when calculated as a percentage of total fat. We think that the 
absolute amount of omega 3 per gram of fish is the more relevant figure.

Supplementation of animal feed with fish oils will not address concerns about the depletion of fish stocks since this will clearly entail the harvesting of even more fish. However, we wanted to highlight that this is a potential approach to increase the dietary consumption of omega 3 oils in people unwilling or unable to eat fish. We acknowledge that the juxtaposition of these two independent points in the text box is rather misleading.

We intentionally focused our article on the marine derived omega 3 fatty acids because of the larger and clearer evidence base. We cannot assume that $\alpha$ linolenic acid confers the same benefits as it is a structurally distinct short chain polyunsaturated fatty acid with only limited conversion in humans to the longer chain eicosapentanoic acid and docosahexanoic acid. ${ }^{2}$

Whereas $\alpha$ linolenic acid may confer cardiac protection as part of a Mediterranean diet, ${ }^{3}$ the direct benefits of $\alpha$ linolenic acid have not been firmly established. We agree that ongoing concerns about fish stocks highlight the need for further trials of $\alpha$ linolenic acid in coronary heart disease.

Jehangir N Din research fellow

jehangirdin@hotmail.com

David E Newby reader

Cardiovascular Research, University of Edinburgh, Edinburgh EH16 4SB

Andrew D Flapan consultant cardiologist

Royal Infirmary of Edinburgh, Edinburgh EH16 4SA

Competing interests: None declared.

1 US Department of Agriculture. Nutrient data laboratory. www.nalusda.gov/fnic/foodcomp/ (accessed 31 Jan 2004) 2 Sanderson P, Finnegan YE, Williams CM, Calder PC, Burdge GC, Wootton SA, et al. UK Food Standards Agency alpha-linolenic acid workshop report. $\mathrm{Br} J \mathrm{Nutr}$ 2002;88:573-9.

3 de Lorgeril M, Salen P, Martin JL, Monjaud I, Delaye J, Mamelle N. Mediterranean diet, traditional risk factors, and the rate of cardiovascular complications after myocardial infarction: final report of the Lyon Diet Heart Study. Circulation 1999;99:779-85.

\section{Making Amends misses the point}

EDITOR-Making Amends says that NHS staff should inform patients of negligent acts. ${ }^{12}$ The chief medical officer's sweetening of the proposed duty of candour with an exemption from disciplinary action if reporting issues of patient safety is well intentioned but wrong.

Every doctor tries to do his or her best to provide good quality care to his or her patients. As doctors, we would be insulted if people were to think that we need to be made less accountable for us to do what any responsible professional should, which is to act in the best interests of patients. Reporting adverse events and errors so that these can be investigated when necessary, and learnt from when possible, is clearly in the best interests of patients' safety.

Of course, it would help secure the maximum compliance with reporting procedure if health professionals could have confidence that when reporting adverse events and near misses they would not face unreasonable consequences as a result. That is already a principle supported by patients' and doctors' groups alike, and an integral part of the "charter of understanding between doctors and people affected by medical accidents," which the charity Action Against Medical Accidents (AvMA) launched with our assistance last year.

We strongly endorse the charity's view that an open and fair culture can be achieved without sacrificing professional accountability or damaging public confidence by providing unnecessary and inappropriate exemptions. Growing support for the charter of understanding and the emerging success of new initiatives to help maintain standards, such as the National Clinical Assessment Authority, which offers retraining to underperforming doctors before suspension becomes an issue, are reassuring signs that a fairer more open culture in medicine is developing.

Michael Baum emeritus professor of surgery,

University College London

Portland Hospital, London W1W 5SN

michael@mbaum.freeserve.co.uk

Additional authors are: Alun Elias-Jones, Brian Hurwitz, Donald Irvine, Graham Neale, Umesh Prabhu-all members of Action against Medical Accidents (AvMA) doctors' group.

Competing interests: All authors are members of Action Against Medical Accidents (AvMA); MB is the chair.

1 Dyer C. NHS staff should inform patients of negligent acts. BMJ 2003;327:7.

Department of Health. Making amends. London: DoH, 2003.

\section{Doctors are tending to be perceived as inherently bad}

EDITOR-In his editor's choice Smith describes how doctors are mangled by "justice." What's bad is bad, what's wrong is wrong, and wrongdoing has to be recognised and criminality punished. However, criminalisation of doctors seems to be the new way forward in society and increasingly in Europe.

Daily in Italy media reports mention the neologism "malasanità" (the bad health service). Everything is perceived as unhealthy or as not providing rapid answers, and every death that is not "expected" is alleged to have been caused by bad doctors who are unable to work and are looking only for money. Such reporting is destroying the relationship between patients and doctors, especially where it needs to be strong-for example, in primary care.

As a result, doctors will find it hard to maintain enthusiasm for their profession. A recent national survey in general practice showed that two out of three general practitioners are burnt out-and not only because of bureaucracy, paperwork, and pressure from health authorities to cut expenses and control their work. The low point is the progressive deterioration in general practitioners' relationships with patients, who don't trust doctors any more but are confrontational and litigious.

The media continually encourage people to ask more and more and to criticise, implying that the law courts are the place to find real health. In this atmosphere the courts are pushed to see doctors as corrupt and bad.

Defensive medicine is growing. It is rare and dangerous now for a doctor to take the initiative and be responsible for a lot of decisions, indications, small operations, and treatments that used to be the natural way of life of a good general practitioner.

Francesco Carelli national representative

EURACT Council, Italian College of General

Practitioners, 20123 Milan, Italy

carfra@tin.it

Competing interests: None declared.

Smith R. Doctors mangled by "justice" BMJ 2004:328:0. (17 January.)

\section{Tsars are the limit}

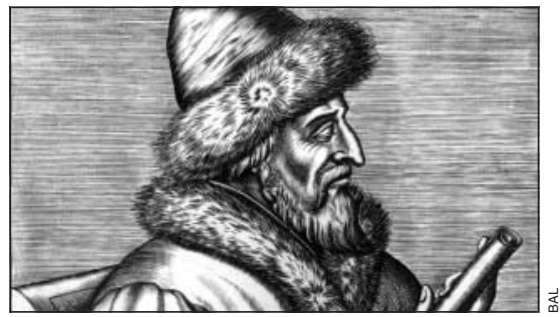

Editor-Russia's tsars were despots. ${ }^{1}$ Their lineage lost ground in the late 19th century and some time later ended in bloody murder. Tsars were not appointed: they inherited power and abused it. Sometimes their power was usurped by those with the ear of the throne.

Peter the Great sought favour with the French court and played at boats with William of Orange. There was only one tsar at a time.

How can a title so suffused in historical imperfection ever be taken seriously? Or was that the intention?

James N Hardy general practitioner principal Bethnal Green Health Centre, London E2 6LL james.hardy@nhs.net

Competing interests: JNH has strong republican tendencies.

1 Burns H. Health tsars. BMJ 2004;328:117-8. (17 January.)

\section{bimj.com}

Letters appearing here are an edited selection of rapid responses originally posted on bmj.com

We ask for all letters to the editor to be submitted as rapid responses via bmj.com

For advice see: bmj.com/rapidresponses 